\title{
Neurologic Manifestations in a Prospective Unselected Series of Hospitalized Patients With COVID-19
}

\begin{abstract}
Juan Carlos García-Moncó, MD, PhD, Antonio Cabrera Muras, MD, Markel Erburu Iriarte, MD, Patricia Rodrigo Armenteros, MD, Alejandra Collía Fernández, MD, Javier Arranz-Martínez, MD, Solange Kapetanovic, MD, Ana Lorenzo-García, MD, Amaia Bilbao González, PhD, and Marian Gomez-Beldarrain, MD
\end{abstract}

Correspondence

Dr. García-Moncó hospit05@sarenet.es

Neurology: Clinical Practice April 2021 vol. 11 no. 2 e64-e72 doi:10.1212/CPJ.0000000000000913

\section{Abstract \\ Background}

An increasing number of neurologic problems are being described in coronavirus disease 2019 (COVID-19) disease, but their frequency and type have not been defined. In this study, we sought to determine the extent of neurologic manifestations of COVID-19 in a prospective series of unselected patients admitted to the general medicine wards of our hospitals due to COVID-19 and who were examined by a team of neurologists.

\section{Methods}

Eight neurologists provided medical attention to patients hospitalized for COVID-19 to provide medical support to other hospital units tasked with the care of an increasingly larger influx of patients with COVID-19. A series of 100 consecutive, unselected patients were evaluated systematically, including a questionnaire that collected medical information derived from the initial examination and the medical history.

\section{Results}

Eighty-eight percent of the patients had 1 neurologic manifestation associated with COVID-19 during hospitalization. Most common were anosmia-dysgeusia and headache (44\% each), myalgias (43\%), and dizziness (36\%). Less frequent were encephalopathy (8\%), syncope (7\%), seizures $(2 \%)$, and ischemic stroke during the period of hospitalization (2\%). Anosmia and headache associated with younger patients with less severe disease, and both were associated with each other and with serum inflammatory markers. Encephalopathy was associated with fever and syncope and with markers of inflammation.

\section{Conclusions}

Neurologic disturbances are common in patients with COVID-19, particularly if patients are evaluated by neurologists. There is a wide variety of neurologic conditions, some of them severe, in the spectrum of COVID-19 disease that will benefit from an evaluation by practicing neurologists.
MORE ONLINE

COVID-19 Resources

For the latest articles, invited commentaries, and blogs from physicians around the world NPub.org/COVID19

The present pandemic of severe acute respiratory syndrome coronavirus 2 (SARS-CoV-2) infection has a primary respiratory component, but in severe cases, the clinical manifestations have included

Osakidetza Basque Health Service (JCG-M, ACM, MEI, PRA, ACF, SK, AL-G, ABG), Basurto University Hospital, Departments of Neurology and Research Unit; and Galdakao Hospital (JAM, MG-B), Vizcaya, Spain.

Funding information and disclosures are provided at the end of the article. Full disclosure form information provided by the authors is available with the full text of this article at Neurology.org/cp. 
disorders of other organ systems. A number of neurologic problems whose exact frequency and type are not well defined have been reported in the very recent literature ${ }^{1-7}$ as well as anecdotally in our own pandemic environment. Clinical information derives mainly from series of respiratory patients in whom neurologic problems may have been missed or underestimated as well as from case reports that do not allow an accurate estimate of the extent and description of these neurologic disturbances.

Our hospitals serve an area that has reported nearly 2,000 cases of coronavirus disease 2019 (COVID-19) from March 20 to April 17, 2020 (our study period). This high case load in such a short period of time nearly overwhelmed the normal functioning of our hospitals making the care of COVID-19 patients a medical priority that required resources from all medical specialties. Thus, a number of neurologists were asked to participate in the care of hospitalized patients with COVID-19. This rapidly evolving pandemic also provided an opportunity to observe the clinical development of the patients from a neurologic perspective.

In this study, we sought to determine the type and frequency of neurologic manifestations of COVID-19 by evaluating a consecutive prospective series of unselected patients admitted to the general wards of our hospitals due to COVID-19 and who were examined by a team of neurologists who assisted in the care of these patients.

\section{Methods}

A team of 8 neurologists ( 4 attending neurologists and 4 residents in their last 2 years of neurology residency) provided medical attention to patients admitted to the hospital due to respiratory or systemic COVID-19. This was part of the plan established at our 2 institutions to provide medical support to other hospital units tasked with the initial care of an increasingly larger influx of patients with COVID-19. The study was conducted at the Hospital Universitario de Basurto and the Hospital de Galdakao, both in Vizcaya, Spain. Both hospitals provide health care to a pooled population of 670,000 inhabitants.

Increasing evidence for neurologic involvement in some of these patients led us to investigate this possibility with a standardized approach. To this end, we designed a questionnaire to verify the neurologic manifestations in a prospective unselected series of patients with COVID-19. The questionnaire reflected the neurologic manifestations already described in the incipient literature of the COVID-19 pandemic. ${ }^{1-5,8-10}$ The questionnaire also collected medical information derived from the initial examination and the medical history of the patient, leading to a more accurate interpretation of any neurologic disturbances and also leading to a detailed neurologic examination if needed.

\section{Patient Selection}

One hundred patients were recruited consecutively in an unselected manner by all 8 neurologists from March 20 to April 17.

\section{Inclusion and Exclusion Criteria}

Patients were eligible if (1) they had respiratory symptoms with the need of supplementary oxygen and a positive reversetranscriptase PCR (RT-PCR) assay for SARS-CoV-2 in a nasopharyngeal swab; (2) they had a chest X-ray or CT scan consistent with COVID-19 pneumonia, and (3) they did not require admission in the intensive care unit (ICU). The CURB65 score for pneumonia severity was used to assess the patient's condition and help determine the need for inpatient treatment. This is a yes/no scale that evaluates confusion, blood urea nitrogen $(\mathrm{BUN})>19 \mathrm{mg} / \mathrm{dL}$, respiratory rate $\geq 30$ per min, systolic blood pressure $<90 \mathrm{~mm} \mathrm{Hg}$ or diastolic $\leq 60 \mathrm{~mm} \mathrm{Hg}$, and age $\geq 65$ years. Scores of $0-1$ indicate a low mortality risk, whereas 2-5 represent a moderate to high mortality risk. Exclusion criteria included an inability to communicate due to speech impairment or significant cognitive impairment.

\section{Variable Collection}

The following variables were collected and introduced anonymously into a registry:

- $\quad$ Age, sex, admission date, and date of disease onset.

- Fever at onset and fever only during admission.

- History of hypertension, dyslipidemia, diabetes mellitus, tobacco use, obesity (body mass index $>30 \mathrm{~kg} / \mathrm{m}^{2}$ ), cardiac disease (type), and respiratory disease (type).

- History of headache (type), stroke, epilepsy, dementia, and others (specify).

- Neurologic symptoms at presentation or during admission: anosmia-ageusia, headache (type), myalgias, dizziness (defined as unsteady gait with no other focal neurologic findings), vertigo, syncope (convulsive or nonconvulsive), encephalopathy (defined as impaired attention and arousal, presenting with confusion, lethargy, delirium, or coma), and seizures.

- Laboratory parameters: serum creatinine, transaminases, creatine kinase (CK), C-reactive protein (CRP), coagulation parameters (international normalized ratio [INR], activated partial thromboplastin time [aPTT]), D-dimer, ferritin, and platelet count.

\section{Data Analysis}

A quantitative descriptive analysis based on percentages and a detailed qualitative analysis of those infrequent conditions that appeared only in a few patients were performed. We analyzed whether there was an association of the main neurologic manifestations with age, sex, laboratory parameters of systemic inflammation (serum CRP, D-dimer, fibrinogen, and ferritin), and disease severity according to the CURB-65 scoring system. We also analyzed the association between different neurologic manifestations.

\section{Statistical Analysis}

The description of the variables was performed using frequency tables, mean and SD, or median and interquartile range (IQR). To study the association between categorical variables, the $\chi^{2}$ or Fisher exact test was used. The nonparametric Wilcoxon test was used to examine the 
differences in quantitative analytic variables according to dichotomous variables. The nonparametric Kruskal-Wallis test was used to examine the differences in quantitative analytic variables according to qualitative polytomous variables. Furthermore, logistic regression models were also performed to study the risk of developing neurologic manifestations according to other characteristics. The results are presented as the odds ratio (OR) and $95 \%$ confidence interval (CI).

A result was considered statistically significant at $p<0.05$. All statistical analyses were performed with SAS for Windows statistical software, version 9.2 (SAS Institute, Inc., Cary, NC).

\section{Standard Protocol Approvals, Registrations, and Patient Consents}

Verbal informed consent was obtained, and none of the patients declined. The process of obtaining verbal informed consent required that relevant risks, benefits, and alternatives be disclosed to the patient and that there be an opportunity to have questions answered. An agreement to proceed was obtained. They were subjected to clinical history and examination as part of their routine and protocolized care. Patients with encephalopathy and seizures gave their consent once they improved enough. The study was approved by the Ethics Committee of the Basque Country.

\section{Data Availability}

Anonymized data not published within this article will be made available by request from any qualified investigator.

\section{Results}

\section{Characteristics of Patients}

One hundred consecutive patients admitted for respiratory COVID-19 disease were enrolled. Seventeen patients were excluded due to the inability to obtain clinical history due to severe cognitive decline or poor general condition. Thus, 117 patients were considered to yield a series of 100 patients for this study.

The characteristics of the patients are described in table 1 . Females constituted $38 \%$, a ratio of 1.6 males to females, and median age was 61 years (range, 37-93 years). The severity of the infection according to the CURB-65 scoring system was classified into low risk (CURB-65 of 0-1) in 65 and moderate to high risk (CURB-65 of 2-5) in 35. No patient scored 5 in this study sample. Sixty-seven percent had concomitant cardiovascular risk factors with hypertension being the most frequent, followed by lipid disorders, diabetes mellitus, smoking, and obesity. Pulmonary disease was present in $24 \%$. Twenty-three patients had prior neurologic disorders that included headache (5, 4 of them migraineurs) and moderate mild impairment that did not preclude history taking. Four patients had a prior stroke. Eight patients had other prior conditions that included Parkinson disease (2), diabetic neuropathy, essential tremor, normal pressure hydrocephalus, meningioma, peripheral neuropathy, and spondylotic myelopathy.

\section{Neurologic Manifestations: Frequency and Distribution}

At least 1 neurologic manifestation was present in $88 \%$ of the patients. Two or more were present in 58\%, and $29 \%$ of patients had 3 or more neurologic disturbances. Seventy-three percent had fever on admission and was persistent in $62 \%$ for several days after admission. The more frequent neurologic disorders during hospitalization included anosmia-dysgeusia and headache (44\% each), myalgias (43\%), and dizziness (36\%, 2 of them had vertigo). The less frequent included encephalopathy ( $8 \%)$, syncope (7\%), seizures (2\%), and ischemic stroke during the period of hospitalization (2\%) (table 2).

Smell and taste dysfunction was described in $44 \%$ of patients by regular history taking, which and probably gives a true estimate of their frequency in this context. Headache was present in $44 \%$ of the patients. Most patients reported a persistent, dull, diffuse, and oppressive pain of moderate intensity, resembling a tension-type headache. Seven patients had migraine-like headaches, but only 2 patients had a history of migraine. None of the patients reported other types of headaches as verified by the evaluating neurologists.

Nonspecific dizziness was present in one-third of the patients. Two patients had isolated vertigo of peripheral type with nystagmus and imbalance.

Myalgias were also frequent, present in $43 \%$ of patients, and were diffuse, with no specific characteristics. Many patients described back pain, possibly of muscle origin.

Encephalopathy was present in $9 \%$ of our patients and had been reported in $8 \%$. Eight of our patients with encephalopathy had a severe disease as indicated by a CURB- 65 score of $2-4$. We did not find an association with inflammatory markers, although the number of patients is low and this aspect should be interpreted with caution. Encephalopathy occurred in most patients in the context of fever and hypoxemia. It coincided with a minor stroke and seizures (1 patient each). One patient developed renal failure with dehydration, metabolic acidosis, and hyperkalemia. Five of these patients had a prior diagnosis of mild cognitive impairment.

There were a number of low-frequency neurologic manifestations in our series that involved syncope, seizures, and stroke. Syncope was present in 7 patients, did not associate with myoclonic jerks, and was of the neurally mediated characteristics in all patients without evidence of cardiac origin.

Seizures were present in 2 patients, one of focal onset and the other one tonic-clonic. The former patient had a fever and mild encephalopathy and presented repeated seizures of focal (frontotemporal) onset that resolved with levetiracetam. The second one had fever and mild encephalopathy and presented a single tonic-clonic seizure that did not recur and did not need specific medication. None of them had a history of epilepsy. 
Table 1 Baseline Characteristics of Patients Hospitalized With COVID-19

\begin{tabular}{|c|c|}
\hline & All patients $(\mathrm{N}=100)$ \\
\hline Variable & $\mathrm{N}$ and $\%^{\mathrm{a}}$ \\
\hline Sex (females) & 38 \\
\hline Age, mean (SD), median (range) & 63.5 (13.9), 61 (37-93) \\
\hline Fever at admission & 73 \\
\hline Fever during admission & 62 \\
\hline \multicolumn{2}{|l|}{ CURB-65 score } \\
\hline 0 & 37 \\
\hline 1 & 28 \\
\hline 2 & 30 \\
\hline 3 & 3 \\
\hline 4 & 2 \\
\hline Cardiovascular risk factors & 67 \\
\hline Hypertension & 45 \\
\hline Dyslipidemia & 33 \\
\hline Diabetes mellitus & 20 \\
\hline Smoking & 16 \\
\hline Obesity (BMI $\geq 30$ kg/m²) & 10 \\
\hline History of cardiovascular disease ${ }^{b}$ & 21 \\
\hline History of pulmonary disease ${ }^{c}$ & 24 \\
\hline Prior neurologic disease & 23 \\
\hline No & 77 \\
\hline Moderate cognitive impairment & 6 \\
\hline Headache & 5 \\
\hline Tension type & 1 \\
\hline Migraine & 4 \\
\hline Other & 0 \\
\hline Stroke/TIA & 4 \\
\hline Others $^{d}$ & 8 \\
\hline
\end{tabular}

Abbreviations: $\mathrm{BMI}=$ body mass index $\mathrm{COPD}=$ chronic obstructive pulmonary disease; COVID-19 = coronavirus disease 2019.

a Because there were 100 patients, the number and percentage coincide.

${ }^{\mathrm{b}}$ History of ischemic cardiopathy or arrhythmias.

${ }^{c}$ COPD or asthma.

d Included Parkinson disease, essential tremor, normal pressure hydro-

cephalus, meningioma, peripheral neuropathy, and spondylitis myelopathy.

Two patients had an ischemic stroke. In one of them, the stroke occurred just before admission and in the other while under our care. Both were considered minor strokes, and while one of them showed neurologic focal findings suggestive of lacunar infarction (hemisensory syndrome with normal brain $\mathrm{CT}$ ), the other one presented as an encephalopathy without focal findings with neuroimaging (brain CT scan) of
Table 2 Neurologic Manifestations Associated With COVID-19 Disease

\begin{tabular}{ll}
\hline Symptom/signs & $\mathrm{N}$ and \% (all patients $=100)^{\mathbf{a}}$ \\
\hline At least 1 neurologic manifestation & 88 \\
\hline$\geq 2$ manifestations & 58 \\
\hline$\geq 3$ manifestations & 29 \\
\hline Anosmia/dysgeusia & 44 \\
\hline Headache & 44 \\
\hline Tension type & 37 \\
\hline Migrainous & 7 \\
\hline Myalgias & 43 \\
\hline Dizziness (unsteady gait) & 36 \\
\hline Vertigo, peripheral type & 2 \\
\hline Encephalopathy & 9 \\
\hline Syncope & 7 \\
\hline Seizures & 2 \\
\hline Focal onset & 1 \\
\hline Generalized & 1 \\
\hline Ischemic stroke during or before \\
admission (1 each)
\end{tabular}

Abbreviation: COVID-19 = coronavirus disease 2019.

a Because there were 100 patients, the number and percentage coincide.

infarction. Both patients had a favorable outcome, and neither had relevant coagulation abnormalities.

\section{Associations Between Clinical Manifestations and Variables of the Study}

The analytical parameters revealed the presence of liver dysfunction in 38\%, kidney failure in 17\%, and increased CK in $25 \%$ (table 3 ). Coagulation parameters (aPTT and INR) were within normal limits, but D-dimer levels were notably increased in most patients. Other markers of inflammation (CRP, fibrinogen, and ferritin) were also markedly elevated.

When grouped by sex (table 4), headache and myalgia were significantly more frequent in women $(\mathrm{OR}[95 \% \mathrm{CI}]=3.60$ [1.54-8.40] and 2.68 [1.17-6.17], respectively), whereas anosmia-dysgeusia and dizziness showed no sex preference. Other neurologic manifestations were not analyzed for associations with other clinical manifestations or laboratory results due to the low number of patients, unsuitable for statistical analysis.

There was a significant association between having headaches and having anosmia-dysgeusia (OR $\left[\begin{array}{ll}95 \% & \mathrm{CI}\end{array}\right]=2.56$ [1.14-5.78] of having anosmia-dysgeusia with the presence of headache), whereas the other main manifestations (dizziness 
Table 3 Laboratory Analyses

\begin{tabular}{|c|c|}
\hline Parameters & All patients $=100$ \\
\hline \multicolumn{2}{|l|}{ Blood chemistry values } \\
\hline $\begin{array}{l}\text { Increased liver enzymes } \\
\text { (GOT >31 U/L, GPT >31 U/L, } \\
\text { and GGT >42 U/L), N and \% }\end{array}$ & 38 \\
\hline $\begin{array}{l}\text { Acute renal failure } \\
\qquad(\mathrm{Cr}>1.1 \mathrm{mg} / \mathrm{dL}), \mathrm{N} \text { and } \%\end{array}$ & 17 \\
\hline Increased CK (>189 U/L), N and \% & 25 \\
\hline Median (IQR) & 320.5 U/L (178-1387) \\
\hline $\begin{array}{l}\text { Coagulation and inflammatory } \\
\text { markers (reference values) }\end{array}$ & Median (Q 25-Q 75) \\
\hline INR (0.9-1.2) & $1(1-1.1)$ \\
\hline aPTT (25-40 s) & $36(32-39)$ \\
\hline Fibrinogen (200-450 mg/dL) & $682(583-783)$ \\
\hline D-dimer $(0-500 \mathrm{ng} / \mathrm{mL})$ & $1028.5(495-3080)$ \\
\hline Platelets per $\mu \mathrm{L}(135,000-450,000)$ & $244,000(194,000-332,500)$ \\
\hline CRP (0-5 mg/L) & $90(37.9-215)$ \\
\hline Ferritin $(30-400 \mu \mathrm{g} / \mathrm{L})$ & $895(379-1713)$ \\
\hline
\end{tabular}

Abbreviations: aPTT = activated partial thromboplastin time; $\mathrm{CK}=$ creatine kinase; $\mathrm{CRP}$ = C-reactive protein; $\mathrm{GGT}$ = gamma-glutamyltransferase; $\mathrm{GOT}$ = transaminases alanine transaminase; GPT = aspartate transaminase; INR = international normalized ratio; IQR = interquartile range.

and myalgias) did not show a significant association. Among the less frequent manifestations, patients with encephalopathy had a higher risk of having syncope $(\mathrm{OR}[95 \% \mathrm{CI}]=10.88$ [1.97-60.15]). The low numbers of patients with seizures and stroke precluded a statistical analysis to verify their potential association with the rest of the variables included in the study.

When the neurologic disorders were analyzed in relation to the inflammatory markers (table 5), headache was found to be associated with a higher CRP $(p=0.0063)$, serum $D$-dimer $(p=0.002)$, and fibrinogen levels $(p=0.0159)$, whereas anosmia-dysgeusia, myalgia, and dizziness were not.
Regarding patients' age, the younger the age, the higher the risk of having anosmia-dysgeusia $(\mathrm{OR}[95 \% \mathrm{CI}]=1.95$ [1.02-1.09]) and headache (OR [95\% CI] = 1.07 [1.03-1.11]), whereas there were no differences in myalgia and dizziness.

The variables were also analyzed in terms of disease severity as reflected by the CURB- 65 scoring system. Of interest, patients with a low CURB-65 score (0-1) showed a higher risk of having anosmia-dysgeusia (OR $[95 \% \mathrm{CI}]=4.03[1.59-10.24])$ or headache $(\mathrm{OR}[95 \% \mathrm{CI}]=4.79[1.83-12.56])$ than those with a more severe condition (CURB-65 2-5).

Myalgias were present in $43 \%$ of patients, although CK was increased in only $23 \%$, with a median value of $320.5 \mathrm{U} / \mathrm{L}$. We found no association between myalgias and $\mathrm{CK}$ values. Eleven of the patients (84.6\%) with elevated CK levels compared with only $4(40 \%)$ of the patients with normal CK levels had myalgia. ${ }^{11}$ No case of rhabdomyolysis was observed.

\section{Discussion}

We present the results of a prospective unselected series of neurologic manifestations in 100 consecutive patients hospitalized for respiratory COVID-19. Our hospitals serve an area of an extremely high case load, one of the largest of this current pandemic.

We found that neurologic manifestations are very frequent in hospitalized patients with COVID-19. Eighty-eight percent of patients present at least 1 neurologic manifestation. This in contrast with the $36 \%$ described in a series from Wuhan, the city origin of the initial outbreak. ${ }^{5}$ In their series, data were retrospective, and their patients were not evaluated directly by neurologists, so this may account for this large difference.

Our results provide the spectrum of neurologic manifestations in unselected patients admitted with respiratory COVID-19 disease, which included anosmia-dysgeusia and headache in $44 \%$ of patients, myalgia in $43 \%$, and dizziness in $36 \%$. Less common were encephalopathy ( $8 \%)$, syncope $(7 \%)$, seizures

Table 4 Analysis of the Main Neurologic Symptoms According to Sex ${ }^{a}$

\begin{tabular}{|c|c|c|c|}
\hline Symptom (n) & Females, n (\%) & Males, n (\%) & OR $(95 \% \mathrm{CI})^{\mathrm{b}}$ \\
\hline Anosmia-dysgeusia (44) & $20(52.63)$ & $24(38.71)$ & $1.76(0.78-3.98)$ \\
\hline Headache (44) & $24(63.16)$ & $20(32.26)$ & $3.60(1.54-8.40)$ \\
\hline Myalgia (43) & $22(57.89)$ & $21(33.87)$ & $2.68(1.17-6.17)$ \\
\hline Dizziness (36) & $18(47.37)$ & $18(29.03)$ & $2.20(0.95-5.10)$ \\
\hline
\end{tabular}

Abbreviations: $\mathrm{OR}=$ odds ratio; $\mathrm{Cl}=$ confidence interval.

a Encephalopathy $(n=8)$, syncope $(n=7)$, seizures $(n=3)$, and vertigo $(n=2)$ were not included due to their low frequency.

${ }^{\mathrm{b}}$ The OR and $95 \% \mathrm{Cl}$ of the presence of each symptom of females vs males. 
Table 5 Association of Inflammatory Parameters With the Main Neurologic Symptoms ${ }^{a}$

\begin{tabular}{|c|c|c|c|c|}
\hline & CRP & Serum D-dimer levels & Serum ferritin levels & Serum fibrinogen levels \\
\hline Symptom (n) & Median (IQR) & Median (IQR) & Median (IQR) & Median (IQR) \\
\hline \multicolumn{5}{|c|}{ Anosmia-dysgeusia } \\
\hline No & $91.8(47.6-215)$ & $1235(598-3148)$ & $728.5(376.5-1606.5)$ & $690(604.5-778)$ \\
\hline Yes & $87.5(28.58-197.5)$ & $950(480-1975)$ & 969 (382-1974) & $673(548-783)$ \\
\hline$p$ Value & 0.5538 & 0.4204 & 0.3465 & 0.7371 \\
\hline \multicolumn{5}{|l|}{ Headache } \\
\hline No & $143.9(57.6-237.5)$ & $1515(734.5-3740)$ & $962(412-1713)$ & 709.5 (629-799.5) \\
\hline Yes & $61.6(21-107.4)$ & $700(410-1650)$ & $677(291-1567)$ & $629(533-724)$ \\
\hline$p$ Value & 0.0063 & 0.0020 & 0.3410 & 0.0159 \\
\hline \multicolumn{5}{|l|}{ Myalgia } \\
\hline No & $91.4(37.9-215)$ & $1330(520-3940)$ & 959.5 (389-1678.5) & 705 (604.5-832) \\
\hline Yes & $80(32.1-213.5)$ & $820(490-1840)$ & $628(360-1971)$ & $650(526-758)$ \\
\hline$p$ Value & 0.5267 & 0.1440 & 0.4896 & 0.0510 \\
\hline \multicolumn{5}{|l|}{ Dizziness } \\
\hline No & $84(37-180)$ & $1080(495-3080)$ & $780(358-1772)$ & $677.5(609-794)$ \\
\hline Yes & $91(37.9-232)$ & $985(500-2815)$ & 988.5 (447.5-1618) & $688(505-775)$ \\
\hline$p$ Value & 0.8456 & 0.8635 & 0.5455 & 0.5120 \\
\hline
\end{tabular}

Abbreviations: $\mathrm{CRP}=\mathrm{C}$-reactive protein; $\mathrm{IQR}=$ interquartile range.

For the comparison of the inflammatory parameters according to neurologic symptoms, the nonparametric Wilcoxon test was used.

${ }^{a}$ Encephalopathy $(n=8)$, syncope $(n=7)$, seizures $(n=3)$, and vertigo $(n=2)$ were not included due to their low frequency.

(2\%), and stroke (2\%). We believe that examination of patients with COVID-19 by neurologists resulted in the higher prevalence of neurologic manifestations in this series.

Headache and myalgia were significantly more frequent in women, whereas anosmia-dysgeusia and dizziness showed no sex preference. Anosmia-dysgeusia and headache patients were younger, whereas no differences were present in myalgia and dizziness. Headache was associated with increased inflammatory parameters (serum CRP, D-dimer, and fibrinogen), but anosmiadysgeusia, myalgia, and dizziness were not. Anosmia-dysgeusia and headache were significantly more frequent in patients with less severe disease, and the opposite was true with headache in a retrospective Chinese series, but in neither case, the difference reached statistical significance. ${ }^{5}$ Myalgias were present in $43 \%$, whereas CK was increased in only $23 \%$.

The frequency and variety of the neurologic problems associated with COVID-19 come from the initial series of respiratory patients of this pandemic. For the purposes of comparison, we pooled data from 7 series. ${ }^{1-5,8,10}$ The aggregated results revealed a lower prevalence of myalgias (median of $27.5 \%$ ) and headache in $8 \%$. Anosmia was not mentioned. That these patients were attended by non-neurologists likely led to an underestimation of the neurologic problems of which only the most severe were recognized. Of interest, when data from a retrospective study of 214 patients were reanalyzed by neurologists, the numbers of and types of manifestations increased. ${ }^{5}$

Anosmia or some degree of smell dysfunction has been reported in a wide range of $5.6 \%-85.6 \%$ of patients, but the method of detection is critical, ranging from self-reports to the administration of a standardized specific questionnaire. ${ }^{5,12-14}$ Forty-four of our patients complained of anosmia-dysgeusia by clinical interview, which likely reflects the figures expected in clinical practice. It should be mentioned that anosmia is not specific for this infection. In a series of 143 consecutive patients with smell dysfunction, 87 of them have had a prior influenzalike illness, a clinical entity known as post-influenza-like hypogeusia and hyposmia, with an estimated incidence of 1 per 400 inhabitants in the United States. ${ }^{15}$ The olfactory sensory neurons do not express 2 key genes coding for angiotensinconverting enzyme 2 (ACE-2) and transmembrane serine protease 2 (TMPRSS 2), two proteins involved in SARS-CoV2 entry. In contrast, olfactory epithelial support cells and nasal respiratory epithelium express both of them, suggesting a nonneural mechanism for anosmia. ${ }^{16}$

Headache was present in $44 \%$ of the patients, and this number contrasts with previous series, where headache was 
present in an average of $12 \%$ (pooled from references 1-4, 9). Headache was present in $13.1 \%$ in a retrospective series of hospitalized patients, ${ }^{5}$ aimed at studying the neurologic manifestations, and was more frequent in severe patients ( $17 \%$ vs 10.3 in nonsevere patients). Headache characteristics have not been defined so far, and therefore, the questioning by a neurologist is of interest. More often, patients complained of a moderate-intensity headache, persistent, dull, and oppressive, resembling a tension-type headache. Most of the patients in our series did not have a history of headache; thus, the headaches may have an origin in the infectious process and did not reflect the worsening of a preexisting primary headache disorder. We found an interesting association of headache with most inflammatory markers, which could suggest a role of inflammation and/or cytokine release in its pathogenesis. Patients who complained of headache had mild-moderate disease severity; this could reflect the fact that in most severe patients, the respiratory problems overshadowed any other symptoms and would be consistent with a lower rate of headaches reported in the initial series of respiratory patients, which tended to have severe disease.

Nonspecific dizziness was present in one-third of the patients, defined as unsteady gait without other focal neurologic findings; only 2 of them had characteristics of vertigo, thus suggesting that dizziness in this population represents a nonspecific symptom in the context of a systemic infection rather than a proper vestibular dysfunction. Our frequency is higher than reported from Wuhan $(9 \%){ }^{9}$

Myalgia was present in $43 \%$ of patients, was more frequent in women $(p=0.0185)$, and was not associated with inflammatory markers. An average of $27 \%$ with myalgia was reported in pooled data from prior series of patients ${ }^{1-3,10,17,18}$ and in $10.7 \%$ of patients in a retrospective Chinese series. ${ }^{5}$ The lack of association between myalgias and $\mathrm{CK}$ values suggests that muscle pain was not due to muscle necrosis but responded to a different origin, perhaps to the effects of systemic inflammation and cytokine release on neuromuscular structures. This aspect will require further clarification.

Less common in this series were encephalopathy, seizures, syncope, and stroke. Although these manifestations were of low frequency, they present a challenge for their severity and life-threatening potential. These problems may be more common in particularly severe patients, often in the ICU setting, ${ }^{19}$ which were not included in this study.

Encephalopathy was encountered in 9 patients, 8 of them with severe disease, and was associated with the presence of fever. Two mechanisms are plausible in this scenario, the indirect effect of the inflammatory cytokine storm of these patients, and the direct effect of the SARS-CoV-2 virus. Although direct viral CNS damage could also contribute to encephalopathy and other neurologic disturbances, RT-PCR in the CSF has been negative in most reported cases so far.
Furthermore, ACE2, the receptor for the virus has only been demonstrated in the endothelium of the nervous system, but not in parenchymal cells. ${ }^{20}$ The only evidence of direct CNS involvement comes from SARS 2002-2003 where viral presence in the brain was detected with real-time RT-PCR, in situ hybridization, and electron microscopy. ${ }^{21,22}$ It is possible that there was greater severity in the neurologic complications of some patients not included in our series, including encephalopathy, as we excluded 17 patients with severe cognitive issues, and we did not approach patients with COVID-19 in the ICU setting.

Seizures were present in 2 patients in our series and have been reported in a few patients to date ${ }^{5,8,23-25}$; we suspect that may be underreported. These numbers may be higher in a series of critically ill patients. No evidence of structural lesions or encephalitis has been found in these patients except for 1 patient, a situation that also occurs in influenza infections. ${ }^{26}$

Loss of consciousness with characteristics of syncope was present in $7 \%$ of the patients, but this condition has not been observed in published series so far. That the information in this study was directly obtained by neurologists in contrast to other specialties less familiar with this condition may reflect this disparity. Impaired consciousness was reported in $7.5 \%$ in a retrospective Chinese series, but it included somnolence, stupor, coma, and confusion. ${ }^{5}$ Syncope did not associate with myoclonic jerks and was of the neurally mediated characteristics in all patients without clear evidence of cardiac origin. However, this needs further clarification because myocardial inflammation and arrhythmias may appear in these patients, could be potentially lethal, and could present as syncope.

Stroke (minor) was present in 2 patients of our series. The true relationship between COVID-19 and stroke incidence remains to be determined. ${ }^{27}$ Despite the fall in stroke admissions, it has been suggested that COVID-19 infection itself may cause stroke. Stroke was reported in 6 cases $(2.8 \%)$ in a Wuhan series, ${ }^{5}$ a frequency similar to ours; all but 1 case occurred in the severe infection group; 5 were ischemic and 1 hemorrhagic. In a New York study, $0.9 \%$ of patients hospitalized for COVID-19 infection had a stroke. ${ }^{28}$

The frequent coagulation abnormalities of patients with COVID-19 together with an exaggerated systemic inflammation and virus-related cardiac injury may all contribute to stroke. ${ }^{27,29}$ Accordingly, stroke severity seems increased in patients with COVID-19 and with poorer outcomes, ${ }^{30,31}$ which contrasts with our 2 patients. However, this needs further studies.

Our study had some limitations: the collection of data had to be balanced with the exigencies of patient care. Moreover, as these patients were in isolation, we were limited as to our ability to perform nonessential examinations or blood collections. As there was no follow-up, our data reflect the observations of a single point in the evolution of the hospitalized patient. We did not include patients in the ICU, so it is 
TAKE-HOME POINTS

$\rightarrow$ Neurologic manifestations are very frequent (88\%) in nonselected patients hospitalized in a non-ICU setting for COVID-19 disease.

$\rightarrow$ The most frequent neurologic disturbances in patients with COVID-19 included anosmia, headache $(44 \%$ each), myalgias (43\%), dizziness or vertigo (36\%). Less common are encephalopathy (9\%), syncope (7\%), and seizures and stroke ( $2 \%$ each).

$\rightarrow$ They represent a diagnostic challenge for the attending neurologist, particularly considering the difficulties in performing routine ancillary examinations in these patients.

\section{$\rightarrow$ Neurologists should be alert to these neurologic} complications because they may represent the debut of an undiagnosed SARS-CoV-2 infection. They can also usually represent a severe condition with evidence of systemic inflammation and coagulation abnormalities that require prompt and specific management measures.
Appendix (continued)

\begin{tabular}{|c|c|c|}
\hline Name & Location & Contribution \\
\hline $\begin{array}{l}\text { Antonio Cabrera Muras, } \\
\text { MD }\end{array}$ & $\begin{array}{l}\text { Basurto University } \\
\text { Hospital }\end{array}$ & $\begin{array}{l}\text { Major role in the } \\
\text { acquisition of data }\end{array}$ \\
\hline $\begin{array}{l}\text { Markel Erburu Iriarte, } \\
\text { MD }\end{array}$ & $\begin{array}{l}\text { Basurto University } \\
\text { Hospital }\end{array}$ & $\begin{array}{l}\text { Major role in the } \\
\text { acquisition of data }\end{array}$ \\
\hline $\begin{array}{l}\text { Patricia Rodrigo } \\
\text { Armenteros, MD }\end{array}$ & $\begin{array}{l}\text { Basurto University } \\
\text { Hospital }\end{array}$ & $\begin{array}{l}\text { Major role in the } \\
\text { acquisition of data }\end{array}$ \\
\hline $\begin{array}{l}\text { Alejandra Collía } \\
\text { Fernández, MD }\end{array}$ & $\begin{array}{l}\text { Basurto University } \\
\text { Hospital }\end{array}$ & $\begin{array}{l}\text { Major role in the } \\
\text { acquisition of data }\end{array}$ \\
\hline $\begin{array}{l}\text { Javier Arranz-Martínez, } \\
\text { MD }\end{array}$ & $\begin{array}{l}\text { Hospital de } \\
\text { Galdakao- } \\
\text { Usansolo }\end{array}$ & $\begin{array}{l}\text { Major role in the } \\
\text { acquisition of data }\end{array}$ \\
\hline $\begin{array}{l}\text { Solange Kapetanovic, } \\
\text { MD }\end{array}$ & $\begin{array}{l}\text { Basurto University } \\
\text { Hospital }\end{array}$ & $\begin{array}{l}\text { Major role in the } \\
\text { acquisition of data }\end{array}$ \\
\hline Ana Lorenzo-García, MD & $\begin{array}{l}\text { Basurto University } \\
\text { Hospital }\end{array}$ & $\begin{array}{l}\text { Major role in the } \\
\text { acquisition of data }\end{array}$ \\
\hline $\begin{array}{l}\text { Amaia Bilbao González, } \\
\text { PhD }\end{array}$ & $\begin{array}{l}\text { Basurto University } \\
\text { Hospital }\end{array}$ & $\begin{array}{l}\text { Performed the statistical } \\
\text { analysis and interpreted } \\
\text { the data }\end{array}$ \\
\hline $\begin{array}{l}\text { Marian Gomez- } \\
\text { Beldarrain, MD }\end{array}$ & $\begin{array}{l}\text { Hospital de } \\
\text { Galdakao- } \\
\text { Usansolo }\end{array}$ & $\begin{array}{l}\text { Analyzed the data and } \\
\text { drafted the manuscript for } \\
\text { intellectual content }\end{array}$ \\
\hline
\end{tabular}

possible that the more severe neurologic manifestations of COVID-19 disease are underrepresented.

In summary, our series disclosed a significant rate of neurologic involvement in patients with COVID-19, and when added to the increasing reports of serious cases of Guillain-Barré syndrome, ${ }^{32,33}$ Miller-Fisher syndrome, ${ }^{34}$ acute necrotizing encephalopathy, ${ }^{35}$ myelitis, ${ }^{36}$ and encephalitis (1 patient with positive RT-PCR in the CSF), ${ }^{25}$ make a strong case for the neurologic consult in the management of patients with COVID-19.

\section{Study Funding}

No targeted funding reported.

\section{Disclosure}

The authors report no disclosures relevant to the manuscript. Full disclosure form information provided by the authors is available with the full text of this article at Neurology.org/cp.

\section{Publication History}

Received by Neurology: Clinical Practice May 12, 2020. Accepted in final form July 16, 2020.

\section{Appendix Authors}

\begin{tabular}{lll}
\hline Name & Location & Contribution \\
\hline Juan Carlos García- & Basurto University & $\begin{array}{l}\text { Designed and } \\
\text { conceptualized the study; } \\
\text { Moncó, MD, PhD, FAAN }\end{array}$ \\
Hospital & $\begin{array}{l}\text { analyzed the data; and } \\
\text { drafted the manuscript for } \\
\text { intellectual content }\end{array}$ \\
\end{tabular}

\section{References}

1. Chang D, Lin M, Wei L, et al. Epidemiologic and clinical characteristics of novel coronavirus infections involving 13 patients outside Wuhan, China. JAMA 2020;323: 1092-1093.

2. Chen N, Zhou M, Dong X, et al. Epidemiological and clinical characteristics of 99 cases of 2019 novel coronavirus pneumonia in Wuhan, China: a descriptive study. Lancet 2020;395:507-513.

3. Guan WJ, Ni ZY, Hu Y, et al. Clinical characteristics of coronavirus disease 2019 in China. N Engl J Med 2020;382:1708-1720.

4. Huang C, Wang Y, Li X, et al. Clinical features of patients infected with 2019 novel coronavirus in Wuhan, China. Lancet 2020;395:497-506.

5. Mao L, Jin H, Wang M, et al. Neurologic manifestations of hospitalized patients with coronavirus disease 2019 in Wuhan, China. JAMA Neurol 2020;77:683-690.

6. Wang Y, Wang Y, Chen Y, Qin Q. Unique epidemiological and clinical features of the emerging 2019 novel coronavirus pneumonia (COVID-19) implicate special control measures. J Med Virol 2020;92:568-576.

7. Wu Y, Xu X, Chen Z, et al. Nervous system involvement after infection with COVID19 and other coronaviruses. Brain Behav Immun 2020;87:18-22.

8. Arentz M, Yim E, Klaff L, et al. Characteristics and outcomes of 21 critically ill patients with COVID-19 in Washington state. JAMA 2020;323:1612-1614.

9. Wang D, Hu B, Hu C, et al. Clinical characteristics of 138 hospitalized patients with 2019 novel coronavirus-infected pneumonia in Wuhan, China. JAMA 2020;323: 1061-1069.

10. Wu C, Chen $\mathrm{X}$, Cai $\mathrm{Y}$, et al. Risk factors associated with acute respiratory distress syndrome and death in patients with coronavirus disease 2019 pneumonia in Wuhan, China. JAMA Intern Med 2020;180:1-11.

11. Wang CC, Chen PY, Wang JD, Liu FC, Huang FL, Lee CY. Clinical and laboratory analysis of influenza B infection in children in Taichung, Taiwan during the 2006-2007 flu season. Pediatr Neonatol 2009;50:54-58.

12. Lechien JR, Chiesa-Estomba CM, De Siati DR, et al. Olfactory and gustatory dysfunctions as a clinical presentation of mild-to-moderate forms of the coronavirus disease (COVID-19): a multicenter European study. Eur Arch Otorhinolaryngol 2020;277:2251-2261.

13. Menni C, Valdes A, Freydin MB, et al. Loss of smell and taste in combination with other symptoms is a strong predictor of COVID-19 infection. medRxiv 2020. doi: 10.1101/2020.04.05.20048421.

14. Vaira LA, Salzano G, Deiana G, De Riu G. Anosmia and ageusia: common findings in COVID-19 patients. Laryngoscope 2020;1:28692.

15. Henkin RI, Larson AL, Powell RD. Hypogeusia, dysgeusia, hyposmia, and dysosmia following influenza-like infection. Ann Otol Rhinol Laryngol 1975;84:672-682.

16. Brann DH, Tsukahara T, Weinreb C, Logan DW, Datta SR. Non-neural expression of SARS-CoV-2 entry genes in the olfactory epithelium suggests mechanisms underlying anosmia in COVID-19 patients. bioRxiv 2020. doi: 10.1101/2020.03.25.009084

17. Liu YC, Liao CH, Chang CF, Chou CC, Lin YR. A locally transmitted case of SARS CoV-2 infection in Taiwan. N Engl J Med 2020;382:1070-1072.

18. Pongpirul WA, Pongpirul K, Ratnarathon AC, Prasithsirikul W. Journey of a Thai taxi driver and novel coronavirus. N Engl J Med 2020;382:1067-1068. 
19. Helms J, Kremer S, Merdji H, et al. Neurologic features in severe SARS-CoV-2 infection. N Engl J Med 2020;382:2268-2270.

20. Ding Y, He L, Zhang Q et al. Organ distribution of severe acute respiratory syndrome (SARS) associated coronavirus (SARS-CoV) in SARS patients: implications for pathogenesis and virus transmission pathways. J Pathol 2004;203:622-630.

21. Gu J, Gong E, Zhang B, et al. Multiple organ infection and the pathogenesis of SARS. J Exp Med 2005;202:415-424.

22. Xu J, Zhong S, Liu J, et al. Detection of severe acute respiratory syndrome coronavirus in the brain: potential role of the chemokine mig in pathogenesis. Clin Infect Dis 2005;41:1089-1096.

23. Karimi N, Razavi A, Rouhani N. Frequent convulsive seizures in an adult patient with COVID-19: a case report. Iranian Red Crescent Med J 2020. doi: 10.5812/ircmj.102828.

24. Lu L, Xiong W, Liu D, et al. New-onset acute symptomatic seizure and risk factors in corona virus disease 2019: a retrospective multicenter study. Epilepsia 2020;61:e49-e53.

25. Moriguchi T, Harii N, Goto J, et al. A first case of meningitis/encephalitis associated with SARS-coronavirus-2. Int J Infect Dis 2020;94:55-58.

26. Ruisanchez-Nieva A, Martinez-Arroyo A, Gomez-Beldarrain M, Bocos Portillo J, García-Moncó JC. Influenza-associated seizures in healthy adults: report of 3 cases. Epilepsy Behav Case Rep 2017;8:12-13.

27. Markus HS, Brainin M. EXPRESS: COVID-19 and stroke-A Global World Stroke Organisation Perspective. Int J Stroke 2020;15:361-364.
28. Yaghi S, Ishida K, Torres J, et al. SARS2-CoV-2 and stroke in a New York Healthcare System. Stroke 2020;51:2002-2011.

29. Oxley TJ, Mocco J, Majidi S, et al. Large-vessel stroke as a presenting feature of Covid19 in the young. New Engl J Med 2020;382:e60.

30. Aggarwal G, Lippi G, Michael Henry B. Cerebrovascular disease is associated with an increased disease severity in patients with coronavirus disease 2019 (COVID-19): a pooled analysis of published literature. Int J Stroke 2020;15:385-389.

31. Larson AS, Savastano L, Kadirvel R, Kallmes DF, Hassan AE, Brinjikji W. COVID-19 and the cerebro-cardiovascular systems: what do we know so far? J Am Heart Assoc 2020;9:e016793.

32. Toscano G, Palmerini F, Ravaglia S, et al. Guillain-Barré syndrome associated with SARS-CoV-2. N Engl J Med 2020;382:2574-2576.

33. Zhao H, Shen D, Zhou H, Liu J, Chen S. Guillain-Barré syndrome associated with SARS-CoV-2 infection: causality or coincidence? Lancet Neurol 2020;19:383-384.

34. Gutierrez-Ortiz C, Mendez A, Rodrigo-Rey S, et al. Miller Fisher syndrome and polyneuritis cranialis in COVID-19. Neurology 2020;95:e601-e605.

35. Poyiadji P, Shahin G, Noujaim D, Stone M, Patel S, Griffith B. COVID-19-associated acute hemorrhagic necrotizing encephalopathy: CT and MRI features. Radiology 2020;296:E119-E120.

36. Zhao K, Huang J, Dai D, Feng Y, Liu L, Nie S. Acute myelitis after SARS-CoV-2 infection: a case report. medRxiv 2020. doi: 10.1101/2020.03.16.20035105. 


\title{
Neurology ${ }^{\circ}$ Clinical Practice
}

\author{
Neurologic Manifestations in a Prospective Unselected Series of Hospitalized Patients \\ With COVID-19 \\ Juan Carlos García-Moncó, Antonio Cabrera Muras, Markel Erburu Iriarte, et al. \\ Neurol Clin Pract 2021;11;e64-e72 Published Online before print July 23, 2020 \\ DOI 10.1212/CPJ.0000000000000913
}

This information is current as of July 23, 2020

$\begin{array}{ll}\begin{array}{l}\text { Updated Information \& } \\ \text { Services }\end{array} & \begin{array}{l}\text { including high resolution figures, can be found at: } \\ \text { http://cp.neurology.org/content/11/2/e64.full.html }\end{array} \\ \text { References } & \text { This article cites } 36 \text { articles, } 3 \text { of which you can access for free at: } \\ & \text { http://cp.neurology.org/content/11/2/e64.full.html\#\#ref-list-1 } \\ \text { Subspecialty Collections } & \text { This article, along with others on similar topics, appears in the } \\ & \text { following collection(s): } \\ \text { COVID-19 } & \text { http://cp.neurology.org//cgi/collection/covid_19 } \\ \text { Encephalitis } & \text { http://cp.neurology.org//cgi/collection/encephalitis } \\ & \text { Information about reproducing this article in parts (figures,tables) or in } \\ \text { its entirety can be found online at: } & \text { http://cp.neurology.org/misc/about.xhtml\#permissions } \\ \text { Permissions \& Licensing } & \text { Information about ordering reprints can be found online: } \\ \text { http://cp.neurology.org/misc/addir.xhtml\#reprintsus }\end{array}$

Neurol Clin Pract is an official journal of the American Academy of Neurology. Published continuously since 2011, it is now a bimonthly with 6 issues per year. Copyright $\odot 2020$ American Academy of Neurology. All rights reserved. Print ISSN: 2163-0402. Online ISSN: 2163-0933.

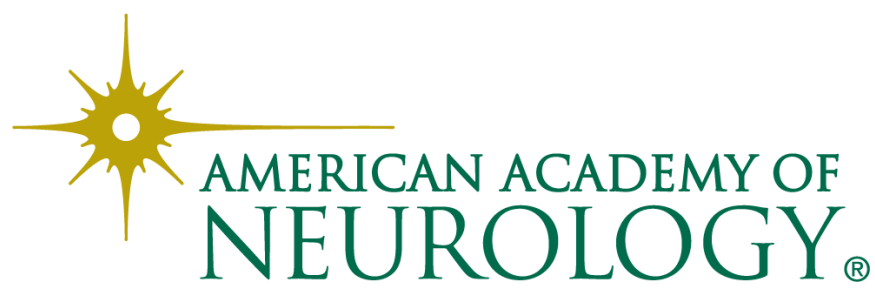

